\title{
Specific immune milk production of cows implanted with antigen-release devices
}

\author{
G. L. Liu, ${ }^{\star} \dagger$ J. Q. Wang, ${ }^{\star} \ddagger^{1}$ D. P. Bu, ${ }^{\star} \ddagger$ J. B. Cheng, ${ }^{\star}$ C. G. Zhang, ${ }^{*}$ H. Y. Wei, ${ }^{\star} \ddagger$ L. Y. Zhou, ${ }^{\star} \ddagger$ K. L. Liu, ${ }^{\star}$ \\ and X. L. Dong* \\ *State Key Laboratory of Animal Nutrition, Institute of Animal Science, Chinese Academy of Agricultural Sciences, Beijing 100193, P. R. China \\ †Shanghai Bright Holstein Co. Ltd., Shanghai 200072, P. R. China \\ $\ddagger$ Ministry of Agricultural Milk and Dairy Inspection and Supervision Center (Beijing), Beijing 100193, P. R. China
}

\section{ABSTRACT}

A new antigen-release device (ARD) that can be implanted to enhance the titer of specific $\operatorname{IgG}$ and concentration of total IgG in milk of lactating cows was evaluated. An immunostimulating complex-based vaccine in the core of the ARD was made from the adjuvant Quil A and type XIII lipase from Pseudomonas spp. with a polylactide acid capsule that was used to control antigen release. Forty lactating Holstein dairy cows were divided into 2 groups $(\mathrm{n}=20)$. All cows in the test group were implanted in the right iliac lymph node with 3 types of ARD at the same time, which were designed to release antigens on different days. The other group was used as a control with no implantation. The 3 ARD were designed to release the antigen on $d$ 0,14 , and 28 after implantation. Specific IgG titers in whey and serum were measured by indirect ELISA, and total IgG concentrations were measured using sandwich ELISA. The results indicated that ARD implantation brought no negative effects on the health status, production performance of cows, and caused neither subclinical nor acute mastitis. The levels of specific IgG in serum $(200,000 \pm 45,000$ vs. $1,200 \pm 360)$ and whey $(41,000$ $\pm 6,000$ vs. $820 \pm 210)$ increased in the cows implanted with ARD. Specific IgG in whey was increased after 9 d. The dynamics of specific IgG titer demonstrated a pattern with the release of the antigen from 3 types of ARD. The average ELISA titer of test group in whey was $41,000 \pm 6,000$, which suggested high efficiency of immune milk production caused by the ARD implantation. For total IgG in milk, greater concentration in the test compared with the control cows occurred from 11 to $20 \mathrm{~d}$ following implantation. The IgG mass was consistent with the dynamics of specific IgG titer and was higher from 15 to $30 \mathrm{~d}$ between test and control group $(7.89 \pm 1.34$ vs. $6.48 \pm 1.17 \mathrm{~g})$. In conclusion, ARD im-

Received February 22, 2008.

Accepted September 8, 2008.

${ }^{1}$ Corresponding author: wang-jia-qi@263.net plantation was effective in improving specific antibody concentration in serum and whey. Furthermore, the whey:serum ratio of specific IgG titer, the milk:serum ratio of total $\mathrm{IgG}$ concentration and total $\mathrm{IgG}$ mass in milk suggested that a transiently upregulated IgG transfer occurred after ARD implantation.

Key words: specific immune milk, immunoglobulin $\mathrm{G}$, antigen-release device, implantation

\section{INTRODUCTION}

Immunoglobulins in milk have several functions including opsonization, complement fixation, prevention of adhesion of pathogenic microbes to the endothelial lining, inhibition of bacterial metabolism by blocking enzymes, agglutination of bacteria, and neutralization of toxins and viruses (Morris et al., 2000; Marnila and Korhonen, 2002). Specific immune milk obtained from cows immunized with various intestinal bacterial or viral antigens can prevent the attachment of pathogens to the epithelial lining, which is a critical step in the establishment of infection (Mehra et al., 2006). Products of immune milk have potential beneficial applications in human and animal healthcare by possibly being used to prevent infections and controlling various disease organisms (Korhonen et al., 2000; Lilius and Marnila, 2001). Immune milk could be a natural, healthy, and safe functional food and may have broad market prospects (Mehra et al., 2006). Therefore, stimulating Ig secretion into milk is an important research focal area for the future (Kolb, 2002).

There has been a great deal of research relating to the transfer of immunity into milk and hyper-immune milk production. The vaccines that have been tested in immune milk production are general vaccines against intestinal pathogens such as Helicobacter pylori and Escherichia coli (Marnila et al., 2003; Tawfeek et al., 2003). Systemic inoculation was shown to be the most effective route for vaccinating cows (Korhonen et al., 2000). Various vaccination methods were used to stimulate the production of Ig in milk such as i.m., i.p., 
s.c., i.v., intranasal, or a combination of these (Hodgkinson and Hodgkinson, 2003). The use of an adjuvant material was a critical factor for eliciting a satisfactory immune response. Adjuvants such as modified cholera toxin, liposomes, microspheres, and propolis enhanced immunity and controlled antigen release (Morris et al., 2000). Nevertheless, several injections were required to maintain a long duration of high specific antibodies concentrations or titers. The most successful approaches took advantage of colostrum or colostrum-based material, from which all commercially available products were derived (Korhonen et al., 2000). Few studies have been conducted to examine specific immune milk production of lactating dairy cows.

Antigen-release device (ARD) implantation is a new method to enhance specific and total IgG in milk. The immunostimulating complex (ISCOM) based vaccine is the core of ARD and is a comprehensive type of antigen transfer system to stimulate the animal to produce IgG. Many vaccines containing the ISCOM-associated antigens were tested in a range of animal models. An antibody response was often achieved with fewer antigens, and the maximal response was reached more quickly (Sjölander et al., 1998; Pearse and Drane, 2004). The device containing the antigen is coated with different concentrations of biodegradable and biocompatible polylactide acid, which can control antigen release. The ARD should release the antigen slowly and have the same effect as giving several vaccinations.

In this study, ARD implantation was used to stimulate specific IgG in milk of lactating dairy cows. Affinity purified lipase from Pseudomonas spp. was used as the antigen. The objectives of this experiment were 1) to examine effects of ARD implantation on the health and milk production and composition of cows; 2) to determine the effect of ARD on development of IgG against injected lipase; 3) to examine the dynamics of titer of specific $\operatorname{Ig} G$ and concentration of total $\operatorname{Ig} G$ in milk and serum; and 4) to evaluate the IgG transfer into milk after ARD implantation.

\section{MATERIALS AND METHODS}

\section{Cows, ARD Implantation, and Sample Collection}

Forty healthy adult multiparous Holstein dairy cows in mid-lactation were randomly divided into 2 groups $(\mathrm{n}=20)$ based on their milk production $(26.0 \pm 3.5$ $\mathrm{kg})$, parity $(2.70 \pm 0.63)$, and DIM $(114 \pm 34)$. The cows used had no signs of mastitis (by checking the presence of redness, swelling, hardness, and pain in the udder, the presence of clots in the milk, and using the California mastitis test) for $2 \mathrm{~m}$ before the start of the trial. The SCC in the milk of the 40 cows was $<200,000$ cells $/ \mathrm{mL}$. All cows were housed under the same conditions, and the diets rations were mixed and fed as TMR 3 times daily.

The ARD were provided by Agri-BIOTECH Company (Perth, Western Australia). The ISCOM-based vaccine, in the core of $\mathrm{ARD}$, was made from the adjuvant Quil A and type XIII lipase from Pseudomonas spp. (Sigma-Aldrich, St. Louis, MO), and lipase was used as the antigen model in this trial. Each capsule of ARD contained $0.76 \mathrm{mg}$ of lipase and $0.25 \mathrm{mg}$ of Quil A. The ARD2 and ARD3 treatments were coated with different concentrations of polylactide acid, which is a patent protective technology. The ARD1 was not coated with polylactide. The ARD were designed to release the antigen at 0,14 , and $28 \mathrm{~d}$ after implantation for ARD1, ARD2, and ARD3, respectively. The diameter and length of ARD1 were 2.3 and $6.2 \mathrm{~mm}$, and those of ARD2 and ARD3 were 5.0 and $10.0 \mathrm{~mm}$, respectively. Each cow in the test group was implanted with all 3 types of ARD in the right iliac lymph node using an implantation gun according to the manufacturer's instructions (Synovex; Fort Dodge, Baulkham Hills, New South Wales, Australia) with a single injection.

The test period began on the day of implantation and lasted $60 \mathrm{~d}$. Individual milk production was recorded every $10 \mathrm{~d}$. Rectal temperature was measured using a thermometer at d 1, 5, and 11 after implantation. Triplicate milk samples were collected once every $2 \mathrm{~d}$ for the first $20 \mathrm{~d}$, every $3 \mathrm{~d}$ from 20 to $40 \mathrm{~d}$, and every $5 \mathrm{~d}$ from 40 to $60 \mathrm{~d}$. The milk samples $(100 \mathrm{~mL})$, a mixture at a 4:3:3 ratio of morning, noon, and evening milk by volume, were analyzed for milk composition, titer of specific IgG, and total IgG concentration. Duplicate blood samples $(10 \mathrm{~mL})$ were collected in vacutainer tubes (BD Biosciences, San Jose, CA) by tail venipuncture and were collected once every $5 \mathrm{~d}$ during the first $20 \mathrm{~d}$ and once every $10 \mathrm{~d}$ from 20 to $60 \mathrm{~d}$. One set of blood samples $(8 \mathrm{~mL})$ was centrifuged at $3,000 \times g$ for 15 min at $4^{\circ} \mathrm{C}$ to separate serum, and the serum samples were frozen at $-80^{\circ} \mathrm{C}$ for further analysis. Another set of blood samples $(2 \mathrm{~mL})$ containing EDTA was used to analyze blood cell counts. Animal care and procedures were approved and conducted under established standards of the Institute of Animal Science, Chinese Academy of Agricultural Sciences, Beijing, China.

\section{Peripheral Blood Leukocyte Count Analysis}

The peripheral blood leukocytes counts were determined on blood samples using an automatic blood cell counter (MEK6318; Nihon Kohden, Tokyo, Japan) according to standard procedures at Xiyuan Hospital of the China Academy of Traditional Chinese Medicine, Beijing, P. R. China. 


\section{Milk Composition Analysis}

The first set of milk samples $(50 \mathrm{~mL})$ was preserved with potassium dichromate and analyzed to determine fat, protein, lactose, total solid, and SCC content by near mid-infrared procedures using a MilkoScan Minor machine (MilkoScan 4000, Foss Electric, Hillerød, Denmark).

\section{Specific IgG Assay in Whey and Serum}

The second set of milk samples $(20 \mathrm{~mL})$ was centrifuged at $480 \times g$ for $15 \mathrm{~min}$ at $4^{\circ} \mathrm{C}$ to remove the fat (Legend Mach 1.6/R, Sorvall, Langenselbold, Germany). Then, $5 \mu \mathrm{L}$ of rennet $(200 \mathrm{mg} / \mathrm{mL}$, Sigma) was added to $10 \mathrm{~mL}$ of milk. The milk samples were kept at $37^{\circ} \mathrm{C}$ for $2 \mathrm{~h}$ and were centrifuged at $4,450 \times g$ for 30 min. The whey samples, collected from the supernatant, were frozen at $-80^{\circ} \mathrm{C}$. Titer of specific anti-lipase $\operatorname{IgG}$ in the whey sample was measured by indirect ELISA using a modification of the method of van Knegsel et al. (2007). Ninety-six-well plates (Costar, Temecula, CA) were coated with $100 \mu \mathrm{L}$ of $5 \mu \mathrm{g} / \mathrm{mL}$ type XIII lipase from Pseudomonas spp. (Sigma-Aldrich) per well and incubated overnight at $4^{\circ} \mathrm{C}$. The plates were washed 3 times with PBS ( $\mathrm{pH} 7.4,0.15 \mathrm{~mol} / \mathrm{L})$ containing 1\% (wt/wt) Tween-20 between each step. The plates were blocked with $200 \mu \mathrm{L}$ of $1 \%$ (vol/vol) human serum solution for $1 \mathrm{~h}$. An aliquot of $100-\mu \mathrm{L}$ serial dilutions of whey (1:2) and serum (1:2) in a washing buffer was added, and dilutions started at 1:200 in whey and 1:800 for serum samples. Two immune whey samples (Agri-BIOTECH) were used as positive controls, and fetal calf serum (Costar) was used as a negative control per plate. The plates were kept at $37^{\circ} \mathrm{C}$ for $2 \mathrm{~h}$. Then, $100 \mu \mathrm{L}$ of donkey anti-bovine $\mathrm{IgG}$ alkaline phosphatase conjugate (1:10,000 diluted) were added to each well.
The plates were again incubated at $37^{\circ} \mathrm{C}$ for $2 \mathrm{~h}$. Finally, ELISA chromogen was diluted to $1.5 \mathrm{mg} / \mathrm{mL}$ in $1 M$ diethanolamine in $0.5 \mathrm{mM} \mathrm{MgCl} \mathrm{m}_{2}$ buffer and was added to the plates. After incubating for $30 \mathrm{~min}$ at $37^{\circ} \mathrm{C}$, the reaction was stopped by adding $50 \mu \mathrm{L}$ of 2 $N \mathrm{NaOH}$ to each well. The absorbance was read at 405 $\mathrm{nm}$ with an ELISA plate-reader (Infinite F200, Tecan, Mannedorf, Switzerland). The reaction was defined as positive when its OD value was more than twice that of the negative control. Titers were expressed as the highest dilution giving a positive reaction. Assay precision was defined by determining intraassay and inter-assay variation. Intraassay variation was determined by 6 successive analyses of the 2 positive controls and the negative control. Interassay variation was evaluated with the 2 positive controls in every plate. The intraassay and interassay coefficients of variation were 3.8 and $6.6 \%$, respectively.

\section{Determination of Concentrations of Total IgG in Milk and Serum}

The third set of milk samples $(30 \mathrm{~mL})$ was centrifuged at $480 \times g$ for $15 \mathrm{~min}$ at $4^{\circ} \mathrm{C}$ to remove the fat. Quantitative determination of total IgG in skimmed milk was performed using commercial bovine IgG quantitation ELISA kits (Bethyl Laboratories, Montgomery, TX) according to the manufacturer's instructions. A standard curve was generated for each set of samples. The dilutions of milk and serum samples were 1:2,000 and 1:8,000, respectively. The intraassay and interassay coefficients of variation were 7.4 and $9.2 \%$, respectively.

The IgG mass of every cow was calculated using a modification of the method of Winger et al. (1995). $\operatorname{Ig} \mathrm{G}$ mass $(\mathrm{g})=\operatorname{IgG}$ concentration $(\mathrm{mg} / \mathrm{mL}) \times$ milk

Table 1. Effects of the antigen releasing device (ARD) implantation on the milk production and composition of cows

\begin{tabular}{|c|c|c|c|c|c|c|}
\hline \multirow[b]{2}{*}{ Trait } & \multicolumn{3}{|c|}{ Treatment $^{1}$} & \multicolumn{3}{|c|}{$P$-value } \\
\hline & Test & Control & SEM & Treatment & Period & Treatment $\times$ Period \\
\hline Milk production (kg) & 21.0 & 22.3 & 2.21 & $\mathrm{NS}^{2}$ & $0.0485^{3}$ & NS \\
\hline $\mathrm{SCS}^{4}$ & 3.40 & 3.41 & 0.69 & NS & NS & NS \\
\hline Milk fat (\%) & 4.23 & 4.04 & 0.18 & NS & NS & NS \\
\hline Milk protein (\%) & 3.43 & 3.35 & 0.07 & NS & $0.0241^{5}$ & NS \\
\hline Lactose $(\%)$ & 4.84 & 4.81 & 0.06 & NS & $\mathrm{NS}$ & NS \\
\hline Total solids (\%) & 13.20 & 12.90 & 0.44 & NS & NS & NS \\
\hline
\end{tabular}

${ }^{1}$ Test $=$ test group, implanted with 3 types of ARD $(\mathrm{n}=20)$; control $=$ control group, without ARD implantation $(\mathrm{n}=20)$.

${ }^{2} \mathrm{NS}=P>0.05$.

${ }^{3}$ Least squares means were $24.8^{\mathrm{a}}, 22.8^{\mathrm{ab}}, 23.0^{\mathrm{ab}}, 20.8^{\mathrm{bc}}, 21.0^{\mathrm{bc}}, 19.2^{\mathrm{c}}$, and $20.1^{\mathrm{bc}}$ for $\mathrm{d} 0,10,20,30,40,50$, and 60 , respectively; ${ }^{\mathrm{a}-\mathrm{c}}$ superscripts indicate that values with different superscripts differ significantly $(P<0.05)$.

${ }^{4} \mathrm{SCS}=\log _{2}(\mathrm{SCC} / 100,000)+3$.

${ }^{5}$ Least squares means were $3.36^{\mathrm{c}}, 3.40^{\mathrm{bc}}, 3.37^{\mathrm{c}}, 3.41^{\mathrm{bc}}, 3.41^{\mathrm{bc}}, 3.43^{\mathrm{bc}}$, and $3.47^{\mathrm{a}}$ for $\mathrm{d} 0,10,20,30,40,50$, and 60 , respectively; ${ }^{\mathrm{a}-\mathrm{c}}$ superscripts indicate that values with different superscripts differ significantly $(P<0.05)$. 


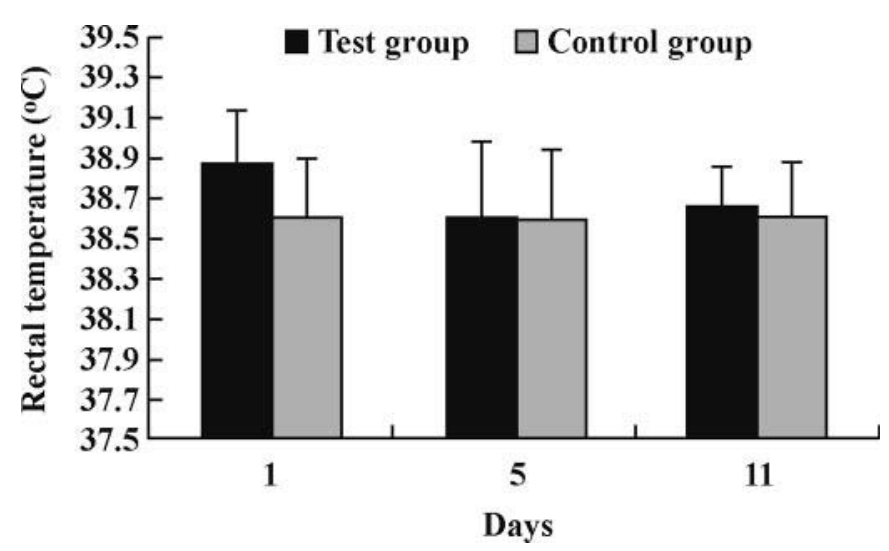

Figure 1. Rectal temperatures of test and control groups after implantation with antigen releasing devices (ARD). Test: Each cow $(\mathrm{n}=20)$ in the test group was implanted with 3 types of ARD, which released antigens at d 0,14 , and 28 after implantation. Control: The control group $(\mathrm{n}=20)$ had no implantation.

yield $(\mathrm{kg}) / 1.032(\mathrm{mg} / \mathrm{mL})$, where 1.032 was the average specific gravity of the milk.

\section{Statistical Analysis}

The data were analyzed using the MIXED model of SAS 9.0 (SAS Institute, Cary, NC). The statistical model included cow (individual animals) as a random effect and period and treatment as fixed effects. The data-specific IgG titer ratio of serum and milk of the test group was analyzed by Duncan's multiple range test. Significance was assumed at $P<0.05$.

\section{RESULTS}

\section{Effects of ARD and the Implantation Operation on Milk Production and Composition}

Following ARD implantation, there was no change of feed intake according to the farm management report, which indicated the cows had normal appetites. The TMR intakes of the test and control groups were 32.6 $\pm 1.4 \mathrm{~kg}$ and $33.0 \pm 2.0 \mathrm{~kg}$, respectively $(P>0.05)$. The results of milk production and composition are in Table 1. Implantation of ARD had no negative effect on milk production, SCC, milk fat, milk protein, lactose, and total solids $(P>0.05)$. The SCC in milk of the test group and control were $132,000 \pm 14,800$ and 133,300 $\pm 25,500$ cells $/ \mathrm{mL}$, respectively $(P>0.05)$. The milk production decreased as DIM progressed $(P<0.05)$, and the milk protein increased $(P<0.05)$.

\section{Wound Healing and Mastitis Assessment Following Implantation}

The wound healing was assessed on $7 \mathrm{~d}$, and there were no obvious symptoms of inflammation after implantation. The cows in the test group had no signs of acute mastitis (by checking the presence of redness, swelling, hardness, and pain in the udder, the presence of clots in the milk, and using the California mastitis test).

\section{Effects of ARD and the Implantation Operation on the Rectal Temperature and Peripheral Blood Leukocyte Counts of Cows}

The rectal temperature of the test group and the control group was $38.87 \pm 0.28^{\circ} \mathrm{C}$ and $38.61 \pm 0.30^{\circ} \mathrm{C}$ on $\mathrm{d} 1$, but was not different $(P>0.05)$. On $\mathrm{d} 5$ and 11 , the rectal temperature of the test group was 38.60 $\pm 0.21^{\circ} \mathrm{C}$ (Figure 1).

The results of the peripheral blood lymphocyte counts are in Table 2 and Figure 2. The white blood cell (WBC), lymphocyte (LYM), and granulocyte (GRA) counts decreased as DIM (or lactation) progressed $(P$ $<0.05)$, whereas the mononuclear leukocyte (MON) counts decreased and then increased. The WBC, LYM, MON, and GRA counts of treated cows were 9,600,000 $\pm 1,760,000,3,730,000 \pm 890,000,620,000 \pm 100,000$ and $5,100,000 \pm 890,000 / \mathrm{mL}$, respectively, and those of control cows were $8,500,000 \pm 1,550,000,3,200,000 \pm$

Table 2. Effects of the antigen releasing device (ARD) implantation on the peripheral blood lymphocyte counts of cows

\begin{tabular}{|c|c|c|c|c|c|c|}
\hline Trait $^{1}$ & \multicolumn{3}{|c|}{ Treatment $^{2}$} & \multicolumn{3}{|c|}{$P$-value } \\
\hline WBC $\left(10^{6} / \mathrm{mL}\right)$ & 9.6 & 8.5 & 0.49 & 0.0469 & 0.0081 & $\mathrm{NS}^{3}$ \\
\hline $\operatorname{LYM}\left(10^{6} / \mathrm{mL}\right)$ & 3.73 & 3.20 & 0.37 & 0.0244 & 0.0204 & NS \\
\hline $\operatorname{MON}\left(10^{6} / \mathrm{mL}\right)$ & 0.62 & 0.53 & 0.05 & 0.0239 & 0.0004 & NS \\
\hline GRA $\left(10^{6} / \mathrm{mL}\right)$ & 5.10 & 4.96 & 0.35 & NS & $<0.0001$ & NS \\
\hline
\end{tabular}

${ }^{1} \mathrm{WBC}=$ white blood cells; LYM = lymphocytes; MON = mononuclear leukocytes; GRA = granulocytes.

${ }^{2}$ Test $=$ test group, implanted with 3 types of ARD $(\mathrm{n}=20)$; control $=$ control group, without ARD implantation $(\mathrm{n}=20)$.

${ }^{3} \mathrm{NS}=P>0.05$. 

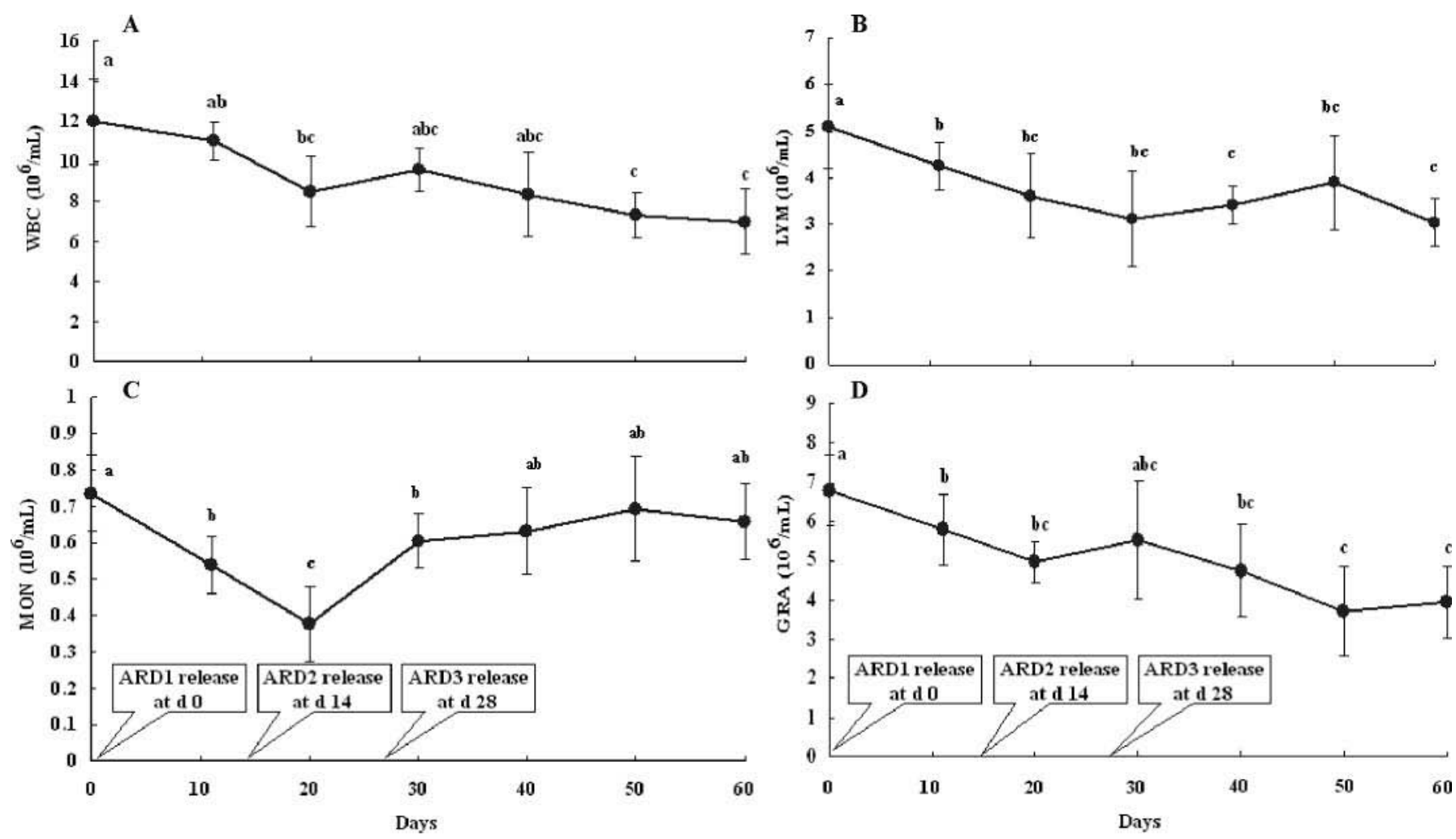

Figure 2. Effects of the antigen releasing device (ARD) implantation on peripheral white blood cells (WBC, panel A), lymphocytes (LYM,

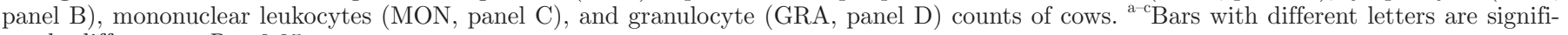
cantly different at $P<0.05$.

$750,000,530,000 \pm 90,000$, and $4,960,000 \pm 790,000 /$ $\mathrm{mL}$, respectively.

\section{Specific IgG Titer in Serum and Whey}

Figure 3 summarizes the specific IgG levels found in serum and whey. The serum levels of specific IgG in all cows in the test group increased after implantation. The specific IgG in serum of the test group was greater after $7 \mathrm{~d}$ and persisted the rest of the test period $(200,000 \pm$ $45,000$ vs. $1,200 \pm 360 ; P<0.01)$. In whey, the immune responses were higher $(41,000 \pm 6,000$ vs. $820 \pm 210$; $P<0.01)$ in the test group and were consistent with the release of the $3 \mathrm{ARD}$. Specific IgG in whey was measured after $9 \mathrm{~d}$ and was greater $(P<0.01)$ than controls and remained greater for the remainder of the trial. Specific IgG in whey of treated cows increased after $9 \mathrm{~d}$ and persisted for only $3 \mathrm{~d}$ and then decreased rapidly, but was still greater $(P<0.01)$ than controls. The average ELISA titer in the whey of the treated cows was $12,000 \pm 1,500$ on d 11. The ARD2 released the antigen on $\mathrm{d} 14$, and the titer in whey climbed to $17,000 \pm 2,200$ and then decreased. The ARD3 released the antigen on $\mathrm{d} 28$, and the titer climbed to another peak $(12,400 \pm 1,900)$ and persisted $10 \mathrm{~d}$ before dropping gradually.

A change of specific IgG titer ratio of serum and milk was observed (Figure 4). Peak levels of IgG in the whey:serum ratios for specific $\operatorname{IgG}$ were found on d 11 and 20 following implantation. On d 11 and d 20 after implantation, the whey:serum ratio was higher $(P<$ $0.05)$ than that of $d 15,50$, and 60.

\section{Effects of the ARD on Total IgG Concentration and Mass in Milk}

Table 3 and Figure 5 show the total IgG concentration in serum and milk. The concentrations of total IgG in milk (Figure 5, panel A) were not different between control and treated cows $(0.44 \pm 0.16 \mathrm{mg} / \mathrm{mL}$ vs. 0.31 $\pm 0.12 \mathrm{mg} / \mathrm{mL}$ ). Total IgG in serum (Figure 5, panel B) increased as DIM progressed, and that of the test group increased on d 20 after implantation. The ratio of concentration of total IgG milk:serum (Figure 5, panel C) decreased as DIM progressed. The total IgG mass in the milk (Figure 5, panel D) of the test and control groups was $7.89 \pm 1.34 \mathrm{~g}$ and $6.48 \pm 1.17 \mathrm{~g}$, respectively. 


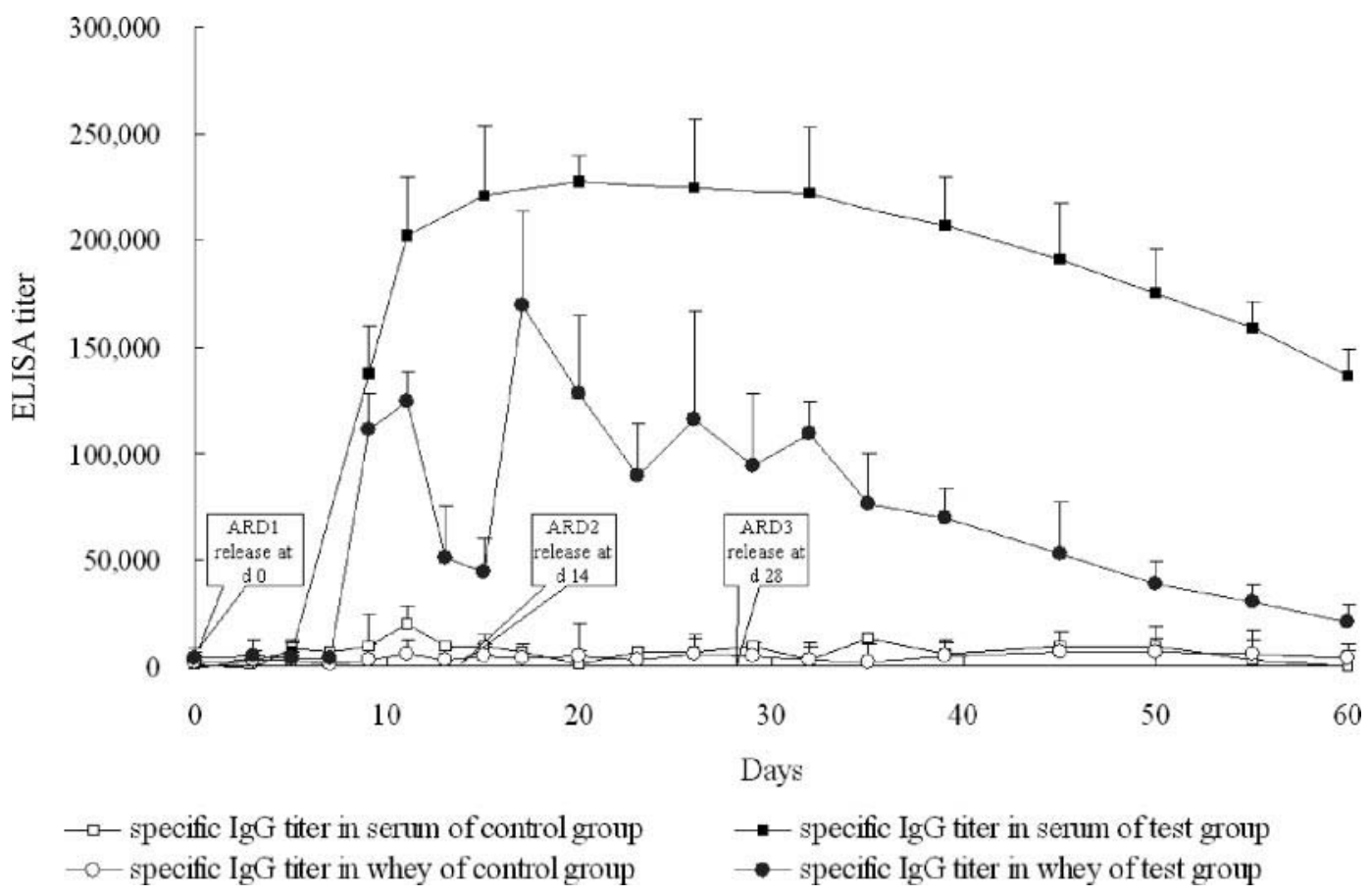

Figure 3. Dynamics of specific IgG production in serum and whey. Each cow $(n=20)$ in the test group was implanted with 3 types of antigen releasing devices (ARD), which released antigens at d 0, 14, and 28 after implantation. The control group $(\mathrm{n}=20)$ was used as a control with no implantation. Specific IgG titer in whey of the test group $(\bullet)$, specific IgG titer in serum of the test group (ם), specific IgG titer in whey of the control group $(\bigcirc)$, specific IgG titer in serum of the control group $(\square)$.

\section{DISCUSSION}

\section{Effects of ARD Implantation on the Health of Cows}

Implantation of hormonal stimulants has been used to improve the growth and efficiency of beef cattle since 1954 (Hancock et al., 1994). The safety of properly administered hormonal implants in beef production is assured when the US Food and Drug Administration (FDA) approves their use. Implant safety is implied by the historical (over $40 \mathrm{yr}$ ) usage in cattle production that has resulted in no observed safety problem.

Whether ARD implantation operation had a negative effect on the health of cows was always a concern for researchers. Judging from the feed intake, milk production, and composition (Table 1) in the present experiment, ARD implantation was not associated with any changes in the production performance or composition in this experiment. The results support those reported by Padula et al. (2003).

There were no acute mastitis cases observed after ARD implantation. Furthermore, the implantation of ARD did not increase the SCC or SCS in milk. The SCC in milk constitutes a good diagnostic tool that allows early detection of either subclinical or acute form of mastitis and is a valuable component of monitoring programs (Green et al., 2004). The SCC for normal milk was $<200,000$ cells $/ \mathrm{mL}$. The SCC in the milk of the test group and control group were all $<200,000$ cells/mL, which indicated no subclinical mastitis occurred. Therefore, the ARD implantation operation induced neither subclinical nor acute mastitis.

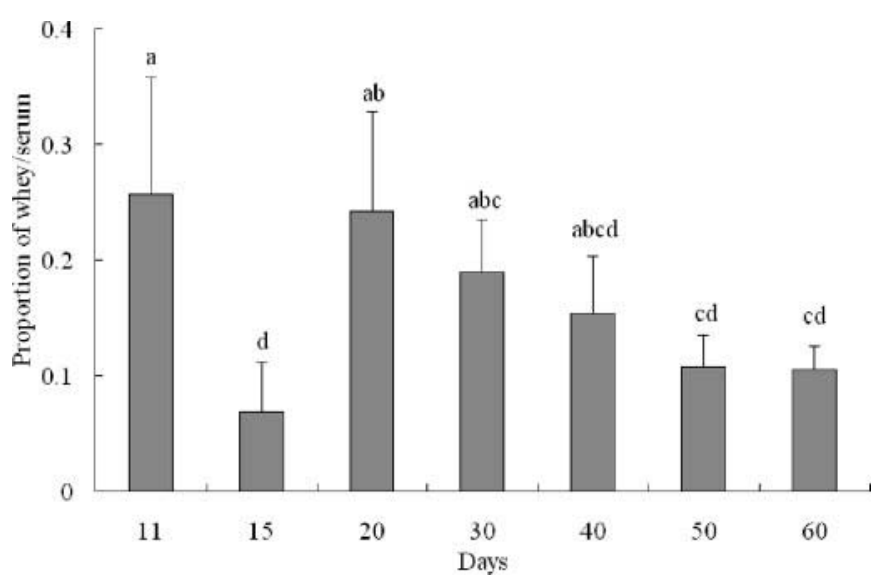

Figure 4. Specific IgG titer ratio of serum and milk of the test group. Each cow $(n=20)$ in the test group was implanted with 3 types of antigen releasing devices (ARD), which released antigens at d 0,14 , and 28 after implantation. ${ }^{\text {ad }}$ Bars with different letters are significantly different at $P<0.05$. 

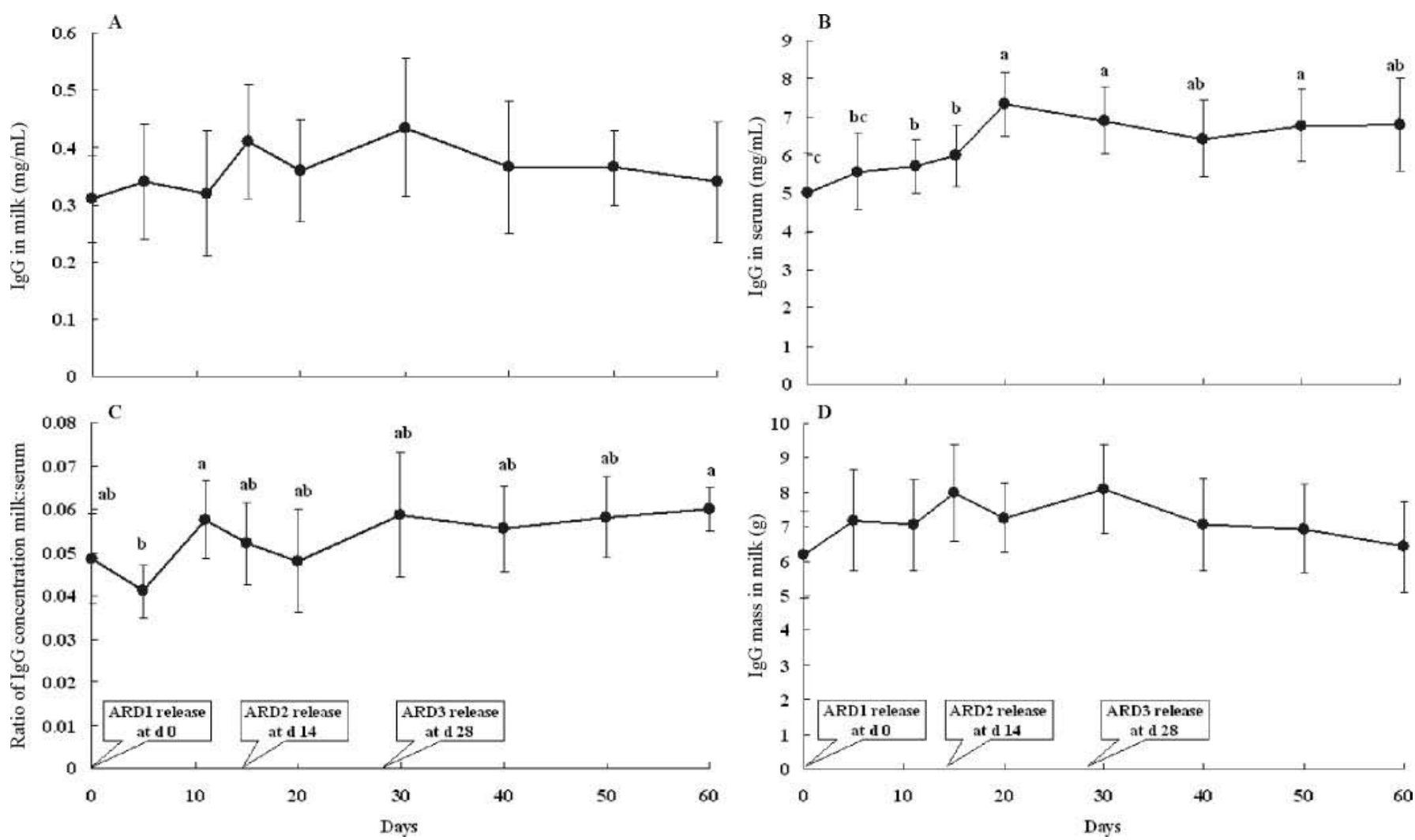

Figure 5. Dynamics of total IgG concentration in milk (panel A) and serum (panel B), ratio of IgG concentration of total IgG milk:serum (panel C), and IgG mass in milk (panel D) and after antigen releasing devices (ARD) implantation. ${ }^{\mathrm{a}, \mathrm{b}}$ Bars with different letters are significantly different at $P<0.05$.

Rectal temperature on d 1 after ARD implantation was $38.87 \pm 0.28^{\circ} \mathrm{C}$. The measured values of rectal temperature were all in the normal range $\left(38.0^{\circ} \mathrm{C}\right.$ to $39.0^{\circ} \mathrm{C}$; Hopster et al., 1998). The measured values of WBC, LYM, MON, and GRA of the test and control group were all in the reference range (WBC: 4,000,000 to 12,000,000/mL; LYM: 600,000 to 5,000,000/mL; MON: 0 to $8,000,000 / \mathrm{mL}$; GRA: $2,000,000$ to $7,000,000 / \mathrm{mL}$; Kulberg et al., 2004), which meant there were no signs of obvious inflammatory response. Therefore, the use of ARD implantation in specific immune milk produc- tion posed no safety risk to the health and production performance of cows.

\section{Dynamics of Specific IgG Production in Serum and Whey}

The administration of foreign antigens into a cow can induce humoral response and stimulate the production of serum antibodies. Several types of Ig are involved in the humoral response, of which $\operatorname{IgG}$ is the main antibody involved (Butler, 1998). Specific IgG in

Table 3. The total IgG concentration and mass in serum and milk after antigen releasing device (ARD) implantation

\begin{tabular}{|c|c|c|c|c|c|c|}
\hline Trait & \multicolumn{3}{|c|}{ Treatment $^{1}$} & \multicolumn{3}{|c|}{$P$-value } \\
\hline Concentration of total IgG in milk (mg/mL) & 0.44 & 0.31 & 0.10 & $\mathrm{NS}^{2}$ & NS & NS \\
\hline Ratio of concentration of total IgG milk/serum & 0.062 & 0.050 & 0.014 & NS & 0.0002 & NS \\
\hline IgG mass in milk (g) & 7.89 & 6.48 & 1.27 & 0.0415 & NS & NS \\
\hline
\end{tabular}

${ }^{1}$ Test $=$ test group, implanted with 3 types of $\operatorname{ARD~}(\mathrm{n}=20)$; control $=$ control group, without ARD implantation $(\mathrm{n}=20)$.

${ }^{2} \mathrm{NS}=P>0.05$. 
milk comes from serum through selective transfer by neonatal $\mathrm{Fc}$ receptors in mammary gland epithelium (Kolb, 2002; Anderson et al., 2006). The dynamics of specific IgG in whey and serum should be similar, and the titer of specific IgG and the concentration of total $\operatorname{IgG}$ in whey should depend on that in serum.

Based on classical immunology, when ARD1 released antigens on $\mathrm{d} 0$ (primary vaccination), it induced the primary immune response. The secondary and booster immune responses took place on subsequent encounters with the same antigens released by ARD2 and ARD3 on $\mathrm{d} 14$ and 28. The lag period of the primary immune response is generally 4 to $7 \mathrm{~d}$; the time of peak response is generally 7 to $10 \mathrm{~d}$. The lag period of the secondary and booster immune response is generally 1 to $3 \mathrm{~d}$, and the time of peak response is generally 3 to $5 \mathrm{~d}$ (Butler, 1998). In our study, the dynamics of specific IgG in whey (Figure 3) were in agreement with the above description and support data from Zhang et al. (2008). They found that the specific IgG was measurable on $d$ 9 in whey and on $\mathrm{d} 8$ in serum after ARD implantation, and total IgG concentration in whey reached to peak at d 9,17, and 32, respectively, corresponding with the release of ARD at d 0,14, and 28. Yet, the $\operatorname{IgA}$ and $\operatorname{IgM}$ concentration failed to show the same regular patterns when compared with IgG (Zhang et al., 2008). In our study, the magnitude of peak antibody response was greater than the primary response, and specific $\operatorname{Ig} G$ in whey reached the second peak with the highest titer on d 17 (Figure 3). Similar results were reported by Liu et al. (2007).

\section{Increased Specific and Total IgG Transfer into Milk of Cows After ARD Implantation}

An increase of specific IgG titer or total IgG concentration in serum and milk was well understood because it coincided with the dynamics of a humoral immune response. In this study, the whey:serum ratio of specific IgG titer had the highest value on d 11 (Figure 4), which suggested that specific IgG transfer into milk increased. Furthermore, the results of the total IgG mass in milk (Table 3) suggested that total IgG transfer into milk increased after ARD implantation in the mammary gland's secretory epithelium. The Ig transfer into mammary secretions was influenced by a variety of factors, including hormonal regulation, physiological status, and genetic effects (Winger et al., 1995; Clawson et al., 2004).

\section{Specific Immune Milk Production by ARD Implantation Compared with Previous Studies}

Most successful experimental approaches took advantage of colostrum or colostrum-based material, from which all of the commercially available products were derived (Korhonen et al., 2000; Scammell, 2001). Many specific immune milk products had been introduced into the commercial market specifically for the healthcare sector. Tawfeek et al. (2003) used 5 strains of $E$. coli (caused diarrhea) to immunize pregnant cows and found specific $\operatorname{IgG}$ in colostrum could lessen incidence of diarrhea and shorten duration of diarrhea episodes. Colostrum is a unique form of milk produced by cow in late pregnancy and a few days after giving birth. The colostrum yield is limited, although very high concentrations of specific and total IgG occur in colostrum. In this study ARD implantation stimulated a specific immune response in milk because there was an increase in IgG mass in milk (Table 3).

In this study, antigen in ARD induced a humoral response (Figure 3), and IgG is the main antibody produced. Morris et al. (2000) reported a protocol to produce greater titers of IgA but not of other Ig. They immunized postcolostrum cows to induce mucosal immunity using Helicobacter pylori antigens and adjuvant modified cholera toxin. The specific milk would be used to treat surface infections (including infections of the skin, respiratory tract, gastrointestinal tract, and urogenital tracts). Hodgkinson and Hodgkinson (2003) provided a process for production of $\operatorname{Ig} \mathrm{A}$ in milk from hyperimmunized mammals using a 3 -route immunization protocol. The first 2 routes of administration selected were i.p. and i.m., and the third route of administration was intramammary. The IgA titers could reach $1.0 \times 10^{5}$; however, the IgA titers varied markedly between individual animals with very high levels observed in just a few animals.

The IgA antibodies, which are produced in smaller amounts than $\operatorname{IgG}$, are considerably more efficient than IgG in biological activities. The IgA can agglutinate antigens, neutralize viruses and bacterial toxins, and prevent the adhesion of enteropathogenic bacteria to mucosal epithelial cells (Marnila and Korhonen, 2002). Therefore, stimulating IgA secretion into milk by ARD implantation is an important objective for future research.

\section{CONCLUSIONS}

In conclusion, there were no detrimental effects on the health status or production performance of cows, and neither subclinical nor acute mastitis was induced by ARD implantation. In whey, the dynamics of specific IgG titer were clear and consistent with the release of the $3 \mathrm{ARD}$ and the primary, secondary, and booster immune response. Therefore, ARD implantation was an effective method for producing immune milk. Further studies of ways to increase the duration of specific antibody in milk are currently underway. 


\section{ACKNOWLEDGMENTS}

We are very grateful to Guan Tay and Stephen Iaschi of the University of Western Australia for their contributions to this work and to Richard O. Kellems of Brigham Young University for his assistance with this manuscript. This work was supported by the Ministry of Science and Technology, Ministry of Agriculture (nyhyzx07-036), National Natural Science Foundation of China (30871837), and State Key Laboratory of Animal Nutrition (2004DA25184-Qing-0801).

\section{REFERENCES}

Anderson, L. C., C. Chaudhury, J. Kim, C. L. Bronson, M. A. Wani, and S. Mohanty. 2006. Perspective-FcRn transports albumin: Relevance to immunology and medicine. Trends Immunol. 7:343348.

Butler, J. E. 1998. Immunoglobulin diversity, B-cell and antibody repertoire development in large farm animals. Rev. Sci. Tech. $17: 43-70$

Clawson, M. L., M. P. Heaton, C. G. Chitko-McKown, J. M. Fox, T P. L. Smith, W. M. Snelling, J. W. Keele, and W. W. Laegreid. 2004. Beta-2-microglobulin haplotypes in U.S. beef cattle and association with failure of passive transfer in newborn calves. Mamm. Genome 15:227-236.

Green, M. J., L. E. Green, Y. H. Schukken, A. J. Bradley, E. J. Peeler, H. W. Barkema, Y. de Haas, V. J. Collis, and G. F. Medley. 2004. Somatic cell count distributions during lactation predict clinical mastitis. J. Dairy Sci. 87:1256-1264.

Hancock, F. R., G. H. Deutschefi, M. K. Nielsens, and D. J. Colburn 1994. Effects of Synovex $C^{\circledR}$ implants on growth rate, pelvic area, reproduction, and calving performance of replacement heifers. J. Anim. Sci. 72:292-299.

Hodgkinson, J. A., and S. C. Hodgkinson. 2003. Processes for production of immunoglobulin A in milk. Agresearch Limited, assignee. NZ Pat. No. 6,616,927.

Hopster, H., J. T. N. van der Werf, and H. J. Blokhuis. 1998. Stress enhanced reduction in peripheral blood lymphocyte numbers in dairy cows during endotoxin-induced mastitis. Vet. Immunol. Immunopathol. 66:83-97.

Kolb, F. A. 2002. Engineering immunity in the mammary gland. J. Mammary Gland Biol. 7:123-134.

Korhonen, H., P. Marnila, and S. H. Gill. 2000. Bovine milk antibodies for health. Br. J. Nutr. 84(Suppl. 1):135-146.
Kulberg, S., P. Boysen, and A. K. Storset. 2004. Reference values for relative numbers of natural killer cells in cattle blood. Dev. Comp. Immunol. 28:941-948.

Lilius, E. M., and P. Marnila. 2001. The role of colostral antibodies in prevention of microbial infections. Curr. Opin. Infect. Dis. 14:295-300.

Liu, G. L., J. Q. Wang, D. P. Bu, C. G. Zhang, J. B. Cheng, H. Y. Wei, L. Y. Zhou, Q. Ding, and C. B. Zhang. 2007. Efficiency evaluation of implantation antigen release devise to produce immune milk of cows. J. China Agric. Univ. 12:5-8. (in Chinese).

Marnila, P., and H. Korhonen. 2002. Immunoglobulins. Pages 19501956 In Encyclopedia of dairy sciences. H. Roginski, J. W. Fuquay, and P. F. Fox, ed. Academic Press, London. UK.

Marnila, P., S. Rokka, L. Rehnberg-Laiho, P. Kärkkäinen, U. T. Kosunen, and H. Rautelin. 2003. Prevention and suppression of Helicobacter felis infection in mice using colostral preparation with specific antibodies. Helicobacter 8:192-201.

Mehra, R., P. Marnila, and H. Korhonen. 2006. Milk immunoglobulins for health promotion. Int. Dairy J. 16:1262-1271.

Morris, A. J., D. W. Gorst, D. R. Telford, L. A. Bishop, and A. D. Higham. 2000. Specific immune milk. Dept of Pathology, Royal Lancaster Infirmary, assignee. UK Pat. No. 2,362,572.

Padula, A. M., M. R. McGowan, and K. L. Macmillan. 2003. Absorbable deslorelin implants (Ovuplant ${ }^{\boxplus}$ ) prolong postpartum anestrus in early ovulating dairy cows. Theriogenology 60:1227-1238.

Pearse, M. J., and D. Drane. 2004. ISCOMATRIXTM adjuvant: A potent inducer of humoral and cellular immune responses. Vaccine 19:2391-2395

Scammell, A. W. 2001. Production and uses of colostrum. Aust. J. Dairy Technol. 56:74-82.

Sjölander, A., J. C. Cox, and I. G. Barr. 1998. ISCOMs: An adjuvant with multiple functions. J. Leukoc. Biol. 12:713-723.

Tawfeek, H. I., H. N. Najim, and S. Al-Mashikhi. 2003. Efficacy of an infant formula containing anti-E. coli colostral antibodies from hyperimmunized cows in preventing diarrhea in infants and children: A field trial. Int. J. Infect. Dis. 7:120-128.

van Knegsel, A. T., G. de Vries Reilingh, S. Meulenberg, H. van den Brand, J. Dijkstra, and H. K. Parmentier. 2007. Natural antibodies related to energy balance in early lactation dairy cows. J. Dairy Sci. 90:5490-5498.

Winger, K., C. C. Gay, and E. T. Besser. 1995. Immunoglobulin Gl transfer into induced mammary secretions: The effect of dexamethasone. J. Dairy Sci. 78:1306-1309.

Zhang, C. G., J. Q. Wang, D. P. Bu, G. L. Liu, J. B. Cheng, X L. Dong, K. L. Liu, H. Y. Wei, L. Y. Zhou, and G. Q. Zhao. 2008. The variation of $\operatorname{IgG} 1, \operatorname{IgA}$ and $\operatorname{IgM}$ concentration in blood and milk of dairy cows after implanting antigen-releasing device (ARD). J. Dairy Sci. (Suppl. 1) 91:58.(Abstr.) 